\title{
FAMÍLIA NA CONTEMPORANEIDADE BRASILEIRA: SENTIDOS EM CURSO
}

\section{FAMILY IN BRAZILIAN CONTEMPORANEITY: SENSES IN COURSE}

\author{
Mara Lucia Martins Rodrigues \\ Universidade do Estado do Mato Grosso \\ Cáceres, Mato Grosso, Brasil \\ Ana Luiza Artiaga Rodrigues da Motta \\ Universidade do Estado do Mato Grosso \\ Cáceres, Mato Grosso, Brasil
}

RESUMO: Neste artigo, propomos, na perspectiva da Análise de Discurso, analisar o modo como os sentidos de família são constituídos na contemporaneidade brasileira em diferentes discursos. Para tanto, o corpus constitui-se de textos da ordem do jurídico e por textos, publicados em blog e jornal, que dizem sobre família em nossa sociedade. Nos textos analisados, observa-se o estabelecimento da disputa de sentidos atribuídos à palavra família, sentidos antagônicos, que instauram diferentes posições-sujeito numa sociedade pelos modos como a palavra família significa.

PALAVRAS-CHAVE: Análise de Discurso; Formação discursiva; Memória discursiva; Família.

\begin{abstract}
In this article, we propose, in the perspective of Discourse Analysis, to analyze the way the family senses are constituted in Brazilian contemporaneity in different discourses. For this purpose, the corpus is constituted of texts of the order of the legal and by texts, published in blog and newspaper, that say about family in our society. In the texts analyzed, we observe the establishment of the dispute of meanings attributed to the word family, antagonistic senses, that establish different subject positions in a society by the ways the word family means.
\end{abstract}

KEYWORDS: Discourse Analysis; Discursive formation; Discursive memory; Family. 


\section{INTRODUÇÃO}

Pensando outras formas de constituição de família na contemporaneidade brasileira, para além daquelas formadas tradicionalmente, propomos, neste trabalho, compreender, na perspectiva teórica da Análise de Discurso, o modo como os sentidos da palavra família são constituídos no discurso jurídico do Artigo 16 da Declaração Universal dos Direitos Humanos (1948) ${ }^{1}$, do Artigo 226 da Constituição Federal do Brasil (1998) e em textos publicados em blogs e jornais, que circularam no momento em que se discutia o Projeto de Lei $\mathrm{n}^{\circ}$. $\underline{6583 / 2013^{2}}$, com vista à institucionalização do Estatuto da Família ${ }^{3}, 2015^{4}$, que discursiviza sobre a família brasileira.

A palavra família na contemporaneidade brasileira tem suscitado debates em distintas áreas do conhecimento, significando família de modos diferentes. Segundo o princípio religioso Cristão, a família é reconhecida como a união entre o homem e a mulher, visando à procriação, à continuidade da espécie humana. Conforme o Livro Sagrado (1990), "um homem deixa seu pai e sua mãe, e se une à sua mulher" $(\mathrm{Gn} 2,24)$. Em Gênesis, encontramos a descrição da criação do mundo e o relato da constituição da primeira família existente na terra - a de Adão e Eva. Simbolicamente este relato representa, pelo discurso mítico, o começo da humanidade, que se pauta na união entre um homem e uma mulher.

O historiador Coulanges (2006, p. 58) afirma que "a familia antiga é mais uma associação religiosa que uma associação natural", nessa dimensão, o casamento funciona como uma forma de unir os cônjuges pelos laços do mesmo culto, das mesmas crenças com o objetivo de manter aceso o fogo sagrado e, consequentemente, "dar origem a um terceiro, apto a perpetuar esse culto". (Idem, p. 73). Não se consideravam os laços sanguíneos ${ }^{5}$ e a posição da mulher era relegada desta história, pois, ideologicamente, "a mulher não transmitia nem a existência, nem o culto". (Idem, p. 81).

\footnotetext{
${ }^{1}<$ http://www.ohchr.org/EN/UDHR/Documents/UDHR Translations/por.pdf $>$. Acesso em: 02/08/2015.

${ }^{2}$ A proposta do Estatuto da Família foi aprovada em duas sessões: 24 de setembro de 2015 e 08 de outubro de 2015, pela Comissão Especial da Câmara dos Deputados. O projeto, de autoria do deputado Anderson Ferreira (PR-PE), foi aprovado em caráter conclusivo, mas encontra-se parado na Câmara Federal. Cf.

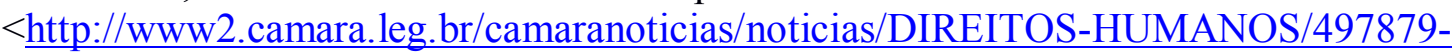

CAMARA APROVA-ESTATUTO-DA-FAMILIA-FORMADA-A-PARTIR-DA-UNIAODE-HOMEM-E-MULHER.html>Acesso em: 11/02/2017.

${ }^{3}<$ http://www.camara.gov.br/proposicoesWeb/prop_mostrarintegra?codteor=1159761 $>$. Acesso em: 20/10/2017.

${ }^{4}$ Até o momento, o Projeto de Lei $n^{0}$. 6583/2013, que visa à criação do Estatuto da Família foi aprovado somente pela Comissão Especial da Câmara dos Deputados, devendo, ainda, ser apreciado pelo Senado e, se aprovado, seguir para a sanção do Presidente da República.

${ }^{5}$ Cf. Coulanges (2006), com o tempo, na Índia, na Grécia e em Roma o parentesco pelos laços sanguíneos e pelo nascimento ganha forças e tem reconhecimento em direito.
} 
Para o jurista Pereira (1959, p. 95), "a família é um fato natural, o casamento é uma convenção social. [...] O homem quer obedecer ao legislador, mas não pode desobedecer à natureza, e por tôda a parte êle constitui a família, dentro da lei se possível, fora da lei, se é necessário". A existência da família precede a instituição jurídica do casamento, o que a torna, segundo o autor, um fato natural. Independentemente, da convenção social, a família sempre existirá.

Do ponto de vista antropológico, Lévi-Strauss $(1967 ; 1982)$ pensa a família a partir do conceito de parentesco que, segundo o autor, se dá pela aliança. Com base neste conceito, o autor propõe pensar o caráter não natural da família, ou seja, "a passagem da natureza à cultura". (1982, p. 62). A constituição da família como fato cultural pressupõe que uma pessoa de um grupo se una a outra pessoa de outro grupo, união fundamental para a existência da sociedade.

Prado (1985, p. 13) define família, na posição de psicóloga, como "uma instituição social variando através da história e apresentando formas e finalidades diversas numa mesma época e lugar". Todo este movimento de formas e finalidades da familia manifesta-se na/pela língua e pelas diferentes condições sócio históricas e políticas. É neste movimento que se engendram os costumes, a cultura e os papeis que determinam a família na sociedade.

Historicamente, como podemos observar, o quadro organizacional da família evolui e, nesse processo, desenha-se, ideologicamente, uma sociedade em que interligada pelo rural e o urbano, o privado e o público, a família ganha novos contornos. A exemplo, a projeção da mulher que passa a ocupar um lugar que lhe permite tomar decisões e ter direitos que até então, eram só extensivos para os homens. Assim, a concepção de família, pelas diferentes perspectivas teóricas, varia conforme o lugar e a posição ideológica que as afeta, sobretudo no que diz respeito ao caráter natural da família.

Desse modo, a questão que mobiliza a interpretação, nesta escrita, é pensar o modo como os sentidos de família são projetados pelo discurso. Neste caso, no discurso jurídico e em textos que circularam na mídia formal e informal durante o processo de tramitação do Projeto de Lei no . 6583/2013.

\section{FAMÍLIA, SENTIDOS INSTITUCIONALIZADOS}

Pensar as condições de produção do termo família implica pensar, tal como diz Orlandi (2010), o movimento dos discursos na história, os sujeitos e a situação. A situação, segundo a autora, pode ser pensada em sentido estrito e sentido lato e, por isso, não podemos dissociar um do outro. Em sentido estrito, temos as circunstâncias da enunciação, o aqui e o agora do dizer. Já em sentido lato temos o contexto sócio- histórico, político e ideológico, ou seja, "o fato de que em uma sociedade como a nossa o saber é distribuído por uma rede institucional, hierarquizada em que o saber relaciona-se ao poder". (Ibidem, p. 15). Além disso, considera-se como parte das condições de produção a memória discursiva, ou seja, o já-dito em outro lugar que constitui e atualiza o dizer. 
Objetivando compreender como os sentidos de família se historicizam nos textos jurídicos, tomamos, para o desenvolvimento das análises, dois documentos oficiais e um Projeto de Lei, que tratam da definição de família.

O primeiro documento trata-se da Declaração Universal dos Direitos Humanos - DUDH $(1948)^{6}$ que, enquanto materialidade simbólica, é um dos primeiros documentos a conceituar família no mundo. Elaborado por representantes de diversos países, época em que o mundo ainda sentia os efeitos da Segunda Guerra Mundial, o documento representa o desejo de preservar a vida e a espécie humana.

Vejamos o Artigo 16, da Declaração Universal dos Direitos Humanos:

1. A partir da idade núbil, o homem e a mulher têm o direito de casar e de constituir família, sem restrição alguma de raça, nacionalidade ou religião. Durante o casamento e na altura da sua dissolução, ambos têm direitos iguais.

3. A família é o elemento natural e fundamental da sociedade e tem direito à proteção desta e do Estado. [grifos nossos]

A formulação nos itens (1) e (3) evoca um conjunto do dizível, histórica e linguisticamente definido (ORLANDI, 2007) sobre a família. No item (1), a família é textualizada como direito do homem e da mulher tanto na constituição familiar como na dissolução, ampliando as relações entre diferentes povos, raças e religião. Essa formulação remete ao contido no $\S 5^{\circ}$ do artigo 226 , da Constituição Federal, que diz: Os direitos e deveres referentes à sociedade conjugal são exercidos igualmente pelo homem e pela mulher, que reafirma o dizível da Declaração Universal dos Direitos Humanos.

No item (3), a definição de família nos remete a Rousseau (1983, p. 23), que defende que o natural, aplicado à família, refere-se "à ideia de necessidade instintiva dos filhos, sem necessariamente remeter ao vinculo biológico com os pais". Assim, na ótica rousseauniana, "a família é considerada um agrupamento natural pelo fato de sua existência preceder ao Estado". (Ibidem). Os sentidos de constituição da família nessas formulações se tocam discursivamente e formam,

\footnotetext{
${ }^{6}$ Outros documentos já haviam sido redigidos em reação a tratamentos desumanos e injustiças, como a Declaração de Direitos Inglesa (elaborada em 1689, após as Guerras Civis Inglesas, para pregar a democracia) e a Declaração dos Direitos do Homem e do Cidadão (redigida em 1789, após a Revolução Francesa, a fim de proclamar a igualdade para todos). Depois da Segunda Guerra e da criação da Organização das Nações Unidas (também em 1945), líderes mundiais decidiram complementar a promessa da comunidade internacional de nunca mais permitir atrocidades como as que haviam sido vistas na guerra. Assim, elaboraram um guia para garantir os direitos de todas as pessoas e em todos os lugares do globo. Cf. <http://www.brasil.gov.br/cidadania-ejustica/2009/11/declaracao-universal-dos-direitos-humanos-garante-igualdade-social $>$. Acesso em: 11/02/17.

${ }^{7}$ Adotada e proclamada pela Resolução no 217 A (III) da Assembleia Geral das Nações Unidas, em 10 de dezembro de 1948.
} 
em seu conjunto, o que Courtine (1994) chama de "domaine de mémoire". Para quem "Le langage est le tissu de la mémoire", ou seja, o domínio da memória é constituído de/por linguagem.

$\mathrm{Na}$ Declaração Universal dos Direitos Humanos (1948), a instituição casamento funciona como um movimento pró casamentos entre um homem e uma mulher. O discurso humanista da DUDH (1948) produz efeitos de sentido de proteção à família, determinada a ser constituída por um homem e uma mulher, de modo a preservar a existência da humanidade. Nesse movimento construído pela linguagem, os sentidos produzidos resultam de relações de um discurso com outro discurso e apontam para discursos futuros sobre família.

No Brasil, a Constituição Federal de (1988) marca um acontecimento histórico, político e de linguagem. Este acontecimento é compreendido pelo discurso como o "ponto de encontro entre uma atualidade e uma memória". (PÊCHEUX, 2008, p. 17). Isto se deve pelo fato de a Constituição Federal (1988), pelo discurso, projetar o imaginário de liberdade e igualdade, o desejo do povo, enquanto sujeito-de-direito, em instaurar a democracia no Brasil, rompendo as barreiras da opressão, perseguição, tortura, ou seja, dos efeitos da ditadura. Nesta tensão entre o que é direito e o que é dever, o sujeito, tal como define Orlandi (2007), é livre e, ao mesmo tempo, assujeitado aos modos de controle do que fica estabelecido na Lei.

Dessa forma, vejamos o modo como o Artigo 226, da Constituição Federal de 1988, diz sobre a família:

Art. 226. A família, base da sociedade, tem especial proteção do Estado. (EC no. 66/2010)

$\S 3^{\circ}$ Para efeito da proteção do Estado, é reconhecida a união estável entre o homem e a mulher como entidade familiar, devendo a lei facilitar sua conversão em casamento.

$\S 4^{\circ}$ Entende-se, também, como entidade familiar a comunidade formada por qualquer dos pais e seus descendentes. [grifos nossos]

Observa-se, inicialmente, que a palavra família aparece predicada por base da sociedade, produzindo a ilusão de um mundo semanticamente homogeneizado. A expressão família, nesse texto, constrói uma rede parafrástica de sentidos - base da sociedade, união estável, entidade familiar, comunidade formada por qualquer dos pais e seus descendentes, em que, em todo dizer há sempre algo que se mantém, isto é, o dizível, a memória. (ORLANDI, 2007). Em outras palavras, "é na linguagem que o sujeito se constitui e também é nela que ele deixa as marcas desse processo ideológico" e histórico. (LAGAZZI, 1987, p. 45). A linguagem é o lugar do possível, do jogo parafrástico e polissêmico, da ambiguidade, do equívoco. É este funcionamento do jogo parafrástico produzido pela linguagem jurídica que entrelaça sentidos que se mantém, mas que também silenciam sentidos outros.

\footnotetext{
${ }^{8}$ Domínio da memória [tradução nossa].

${ }^{9}$ A linguagem é o tecido da memória [tradução nossa].
} 
A linguagem jurídica produz esse efeito de naturalização, como se o sentido estivesse na literalidade. As relações de poder que se estabelecem no discurso são simbolizadas e, na instância do discurso, sentidos e sujeitos são divididos. Parafraseando Orlandi (2011), é o político presente no discurso.

Outro ponto a observar é o $\S 3^{\circ}$ - Para efeito da proteção do Estado, é reconhecida a união estável entre o homem e a mulher como entidade familiar, devendo a lei facilitar sua conversão em casamento, a posição do Estado mostrase marcada em relação ao reconhecimento da união estável, ao instituir proteção e facilitar a conversão da união em casamento, excluindo dessa ação toda união que não constitua estabilidade. Entendemos, por esse parágrafo, que o Estado é peremptoriamente contrário aos tipos de união que não correspondam ao modelo padrão cristalizado na sociedade.

"Ao atestar o que pode ser, a lei exclui automaticamente as possibilidades do não-dito; tudo o que não é mencionado é proibido" (LAGAZZI, 1987, p. 40) e, assim (re)produz-se, na sociedade, o discurso que naturaliza os sentidos de família e silencia sentidos pela força coercitiva do Estado representado na Lei. O modo como constitui-se o Artigo 226 nos remete ao que diz Orlandi (2007, p. 73 74) sobre o silenciamento, que para ela, é constitutivo e significa. Ao dizer " $x$ " para não (deixar) dizer "y", apagam-se "os sentidos que se quer evitar, sentidos que poderiam instalar o trabalho significativo de uma "outra" formação discursiva, uma "outra" região de sentidos". Assim, o sujeito, na posição sujeitolegislador, inscreve o seu dizer numa formação discursiva que normatiza, determina modos de significar. Dizer que a palavra família significa "x", "é afirmar essa articulação de formações discursivas dominadas pelo interdiscurso". (ORLANDI, 2007, p. 44).

A constituição histórica da memória do que é família e os modos como esses sentidos são administrados pelo jurídico se dão por meio do que Courtine (1999, p. 16) apud Payer (2006, p. 26) chama de "línguas de Estado", ou seja, elas preenchem "a memória coletiva com certos enunciados, cuja recorrência organizam, enquanto se dedicam à anulação e empobrecimento de outros". Podemos dizer que as línguas de Estado funcionam nos textos jurídicos estabilizando, pelo efeito ideológico, os sentidos de família em nossa sociedade.

Outro ponto a ser considerado, o modo como o texto Constitucional significa, reverbera sentidos que se sustentam nas relações de forças, em relações hierárquicas, isto é, o Estado diz e as demais leis são (re)elaboradas e funcionam como porta-voz do Estado, normatizando sentidos pelo efeito parafrástico, que é o processo pelo qual algo sempre se mantém.

Podemos dizer que o Brasil, dos anos 80, passou por grandes transformações política, histórica, social e cultural. As mulheres conquistaram a liberdade sexual, o direito à pílula, a ter uma profissão, a participar da vida política do país, e o imaginário de casamento 'felizes para sempre' deslizou para 'felizes enquanto dure'. O casamento convencional perdeu espaço para o casamento por amor e o divórcio deixou de ser tabu.

Assim, no Brasil, a discussão em torno do conceito de família, toma corporeidade, sobretudo, a partir da segunda década do século XXI. Em 2010, 
por exemplo, havia mais de 60 mil casais homossexuais ${ }^{10}$. Desta maneira, questões que dizem respeito aos direitos do casal homoafetivo, sobre herança, pensão alimentícia e previdenciária, licença médica, inclusão do companheiro como dependente em planos de saúde, entre outros benefícios vieram à tona.

O Instituto Brasileiro de Geografia e Estatística - IBGE $\left(2010^{11} \text { e } 2014\right)^{12}$ mostrou, por meio do censo demográfico, que o modelo familiar prescrito na Constituição Federal (1988) não é o único na sociedade, o estudo realizado pelo IBGE (2010), "confirma [...] reflexo da mudança estrutural dos grupos familiares [...]" e, pelo IBGE (2014), registrou-se o aumento de casamentos gays no Brasil, que passou a "representar $0,35 \%$ do total de casamentos realizados no país".

Em 2011, o Supremo Tribunal Federal institui a união estável para casais do mesmo sexo. E em 2013, o Conselho Nacional de Justiça regulamenta, por meio da Resolução No 175 de 14/05/2013, "a habilitação, celebração de casamento civil, ou de conversão de união estável em casamento, entre pessoas de mesmo sexo", discurso que condiz com a posição do Supremo Tribunal Federal.

No mesmo ano, 2013, tramita, na Câmara Federal, o Projeto de Lei $\mathrm{n}^{\circ}$. 6.583/2013, que visa à instituição do Estatuto da Família. A proposta aprovada pela Comissão Especial dos Deputados Federais, em 2015, ainda não foi votada pelo Congresso. Um dos pontos conflitantes desse Projeto está contido no Artigo $2^{\circ}$, da proposta do Estatuto da Família que apresenta um conceito de família centrado na união entre homem e mulher, extensivo a qualquer dos pais e seus descendentes, intervindo na união de famílias e de seus descendentes contrários ao modelo tradicionalmente imposto, provocando, desse modo, em distintas posições sujeito sentidos contraditórios.

Vejamos:

\begin{abstract}
Art. $2^{\circ}$
Para os fins desta Lei, define-se entidade familiar como o núcleo social formado a partir da união entre um homem e uma mulher, por meio de casamento ou união estável, ou ainda por comunidade formada por qualquer dos pais e seus descendentes. [grifos nossos]
\end{abstract}

O Artigo $2^{\circ}$, da proposta do Estatuto da Família (2015), é costurado semântico-linguisticamente pela memória discursiva, que evoca o Artigo 226 da Constituição Federal de 1988, que reconhece a união estável entre o homem e a mulher como entidade familiar. Embora a expressão ou ainda produza a ilusão de acréscimo de outros modelos familiares, não ditos na Constituição Federal (1988), o artigo em análise, mantém o já-dito no texto Constitucional.

${ }^{10} \mathrm{Cf} . \quad<$ http://g1.globo.com/brasil/noticia/2011/04/censo-2010-contabiliza-mais-de-60mil-casais-homossexuais.html>. Acesso em: 06/06/2017.

${ }^{11} \mathrm{Cf} . \quad<$ http://veja.abril.com.br/noticia/brasil/a-nova-familia-brasileira-ibge/>. Acesso em: 26/09/2016.

${ }^{12}$ Cf. $\quad<$ http://g1.globo.com/bom-dia-brasil/noticia/2014/12/ibge-divulga-dados-sobrecasamento-gay-no-brasil-pela-primeira-vez.html> . Acesso em: 26/09/2016. 
Compreendemos que a proposta do Estatuto da Família (2015) se dá em condições de produção distintas em que questões "são silenciadas pelo efeito ideológico que opacifica a especificidade do discurso e trabalha o efeito de naturalização dos sentidos". (MOTTA, 2013, p. 201). Por outro lado, observa-se que os sentidos naturalizados de família deslizam para outros sentidos discursivizados no gesto de reconhecimento da união homoafetiva, pelo Supremo Tribunal Federal (2011) e de regulamentação da união homoafetiva, pelo Conselho Nacional de Justiça (2013).

Assim, os sentidos estão sempre em curso, não se fecham, tampouco são evidentes. Os sentidos estão em jogo com a ausência, com os sentidos do nãosentido. Quando escolhemos uma parte do dizível, deixamos de lado outras e isso também significa porque a nossa relação com os sentidos é determinada pela história, pelo equívoco e pelo jogo da língua.

Para Pêcheux (1997, p. 82) todo processo discursivo supõe a existência "de formações imaginárias que designam o lugar que A e B se atribuem cada um a si e ao outro, a imagem que eles se fazem de seu próprio lugar e do lugar do outro". Desta maneira, é preciso considerar quem diz, para quem se diz. No processo discursivo dos textos jurídicos há a projeção ideológica de um modelo ideal de família, ou seja, "A e B designam lugares determinados na estrutura de uma formação social", e estes lugares estão representados por sujeitos que são imagens resultantes de projeções de A ou de B na relação discursiva.

\section{FAMÍLIA, SENTIDOS EM MOVIMENTO}

No Artigo $2^{\circ}$, da proposta do Estatuto da Família (2015), o termo família produziu inúmeras manifestações ${ }^{13}$ nos diversos segmentos de nossa sociedade. $\mathrm{O}$ documento privilegia família como aquela constituída por - homem e mulher, extensivo a qualquer dos pais e seus descendentes. Há um silenciamento sobre outros modelos familiares aí.

De modo que de um lado, representantes de movimentos sociais diversos, entre eles, LGBTs, manifestaram-se contra a aprovação do Estatuto, em sessão na Câmara dos Deputados, através de palavras de ordem: "Abaixo o estatuto, viva as famílias..." e cartazes em que se classifica o Estatuto da Família de "discriminatório", "homofóbico", "machista", "patriarcal" e "inconstitucional". De outro, a bancada religiosa, representada por evangélicos e católicos, se inscrevem em uma formação discursiva como a de quem aprova a definição de família dada no texto do Estatuto pela Câmara dos Deputados ${ }^{14}$.

${ }^{13} \mathrm{Cf}$. $<$ http://www2.camara.leg.br/camaranoticias/radio/materias/RADIOAGENCIA/49 8832-ESTATUTO-DA-FAMILIA-DEPUTADOS-APRESENTAM-RECURSO-PARAVOTACAO-EM-PLENARIO.html>. Acesso em: 20/02/2017.

${ }^{14}<$ http://www2.camara.leg.br/camaranoticias/radio/materias/RADIOAGENCIA/49883 2-ESTATUTO-DA-FAMILIA-DEPUTADOS-APRESENTAM-RECURSO-PARAVOTACAO-EM-PLENARIO.html>. Acesso em: 06/11/2017. 
Na proposta do Estatuto (2015) a definição do termo família se mantém tal qual como na Constituição Federal (1988). Por outro lado, em nossa sociedade, a palavra família transpõe os limites do que se determina no texto jurídico. Assim, podemos dizer que o sentido da palavra família não existe em si, considerando que as palavras mudam de sentido conforme as posições de quem as empregam.

Tomamos, para as análises que seguem, alguns recortes de textos que circularam em mídias formais e informais, em 2015. Estes textos compõem o conjunto de textos do arquivo midiático que significam família diferentemente dos textos jurídicos.

Dos recortes, destacamos o primeiro, formulado por Renata Campello ${ }^{15}$, publicado no Jornal Zero Hora ${ }^{16}$, em 2015, sob o título "O que é família, afinal?"

R1. Família é quem cuida, ama, instrui, humaniza, transmite valores, apresenta o que conhece de bom no mundo, protege, é presente, troca incontáveis fraldas, levanta de madrugada, conta histórias antes de dormir, leva pra escola, faxina a casa, cozinha, trabalha. E tudo isso, afirmo com gratidão e orgulho, nossos pais fizeram. Houve falhas, não nego: porém falhas, todos temos. Mas será que suas vitórias e falhas têm a ver com sua orientação sexual? Eu e minha irmã estudamos, produzimos, trabalhamos, procuramos respeitar as pessoas e o mundo a nossa volta. Somos até bem "caretas" - minha mãe principalmente. E, por acaso, nenhuma das filhas é lésbica. Ainda temos a sorte de termos nascido, modéstia à parte, lindas, livres e saudáveis igualzinho à mãe. E não venham falar de figura paterna ou materna. Talvez precisemos de tais figuras em dados momentos, mas então quer dizer que famílias compostas por mães solteiras (caso de inúmeras famílias) ou pais solteiros não são famílias? Quer dizer que teremos sérios distúrbios ou desvios psicológicos no futuro caso criados por pais adotivos (homossexuais ou não), mães solteiras, pais solteiros, avós ou avôs? Quer dizer que todas "as famílias brasileiras", tradicionais e compostas por um casal convencional de genitores, criam super-homens e mulheresmaravilha? Resta-me apenas concluir que quem tem o conceito de família baseado no que pregam os que se dizem "pró-família", ou é pequeno de espírito, assaz ignorante, ou não sabe o que é família. [grifos nossos].

O recorte (R1) coloca em relevo a concepção de família, a partir do dizer da autora (filha de mãe homossexual), que vivencia uma nova constituição familiar, que ideologicamente se rompe com o prescrito no discurso jurídico. $\mathrm{O}$ que se observa, no excerto, é que a noção de família significa e se significa pela convivência, pelo afeto, tal como é definida pela autora: Família é quem que cuida, ama, instrui, humaniza, transmite valores, apresenta o que conhece de

\footnotetext{
${ }^{15}$ Aluna do curso de Letras, da UFRGS.

${ }^{16}$ Texto publicado em: <http://zh.clicrbs.com.br/rs/noticias/eleicoes-2014/noticia/2014/ 10/renata-campello-o-que-e-familia-afinal-4611697.html>. Acesso em: 04/09/15.
} 
bom no mundo, protege, é presente, [...], conta histórias antes de dormir, leva pra escola, faxina a casa, cozinha, trabalha. Esse modo de interpretar a palavra família, dadas as condições de produção, se reveste de outros sentidos que rompem com o imaginário de família cristalizado nas Leis e na proposta do Estatuto.

Os sentidos da palavra família atribuídos nas Leis DUDH (1948), Constituição Federal (1988) e na proposta do Estatuto da Família (2015) se movimentam intersubjetivamente para não alterar o modelo imposto à sociedade. Entretanto, o sentido da palavra família desliza, construindo novos sentidos. Este outro modo de compreensão do que seja família se apresenta nas novas formas de constituição familiar que altera as relações entre o jurídico e o social, desnaturalizando sentidos institucionais cristalizados na discursividade das novas uniões. (ZATTAR, 2011).

Para Pêcheux (2009), o sujeito é constituído pelo inconsciente e pela ideologia, que são estruturas-funcionamento que se apresentam distintamente pela/na linguagem, funcionando como que imbricadas no discurso. Em (R1), o questionamento no título "Afinal, o que é família?" atualiza os pré-construídos que funcionam nas discursividades de sujeitos representados por as famílias compostas por mães solteiras (caso de inúmeras famílias) ou pais solteiros não são famílias? [...] pais adotivos (homossexuais ou não), mães solteiras, pais solteiros, avós ou avôs?, que discordam do que define o jurídico sobre a constituição familiar. Assim, há no real da sociedade outros modos de constituição familiar, rompendo com a ilusão da "produção do sentimento de unicidade do sentido ${ }^{17}$ " de família tal como se lineariza no texto jurídico.

À questão apontada no texto, "as famílias brasileiras", tradicionais e compostas por um casal convencional de genitores, criam super-homens e mulheres-maravilha?, a formulação se constitui por um tom de ironia ao questionar os resultados da criação dos filhos por famílias tradicionais como super-homens e mulheres-maravilha. Os nomes super-homens e mulheresmaravilha remetem aos heróis, personagens em quadrinhos ${ }^{18}$, que se representam por um imaginário de força, coragem, felicidade, determinação. Essa questão, no texto, atualiza a memória discursiva de que filhos de famílias tradicionais seriam pessoas sempre bem resolvidas, bem-sucedidas? A questão incide por jogar com o interlocutor, fazer pensar o que se depreende como família e o gesto de bem educar.

Foucault (1971, p. 2) afirma que "o discurso não é simplesmente aquilo que traduz as lutas ou os sistemas de dominação, mas é aquilo pelo qual e com o qual se luta, é o próprio poder de que procuramos assenhorear-nos". Nesta relação, pensamos este poder como pertencente à ordem da linguagem e, que, assenhorear-se da linguagem implica pensar as relações de sentidos do texto. Ao

${ }^{17}$ Cf. Orlandi, 2008, p. 44.

${ }^{18} \mathrm{O}$ super-homem é um personagem criado por Jerry Siegel e Joe Shuster, teve sua primeira aparição em junho de 1938. A mulher-maravilha, outra personagem criada por William Moulton Marston e Harry G. Peter, teve sua primeira aparição em dezembro de 1941. 
dizer, o sujeito assume a responsabilidade pelo que diz, como diz, pela posição que ocupa no dizer, ou seja, o sujeito afetado por outros dizeres, identifica-se com alguns sentidos e não com outros, inscrevendo-se numa matriz de sentidos de uma formação discursiva. É o discurso seguindo seu curso no/pelo jogo realizado pela linguagem, que o sujeito se significa.

Desta forma, no texto (R-1), ao dizer que Resta-me apenas concluir que quem tem o conceito de familia baseado no que pregam os que se dizem "prófamilia", [...] não sabe o que é família, na posição sujeito-filha, mostra que sabe lidar com as diferenças impostas pelo Estado.

Já no texto recorte (R2), formulado por Rodrigo Cunha, Presidente do Instituto Brasileiro de Direito de Família, publicado em $2015^{19}$, é dito que:

R2. A família não é mais singular. Ela é plural, tem inúmeras representações sociais. [...] o Brasil é um Estado laico ou, pelo menos, pretende ser um Estado laico. Colocar essa imposição de que família é só a união de homem e mulher, isso aí é um retrocesso histórico enorme. [...] Família é uma estruturação psíquica, onde cada membro ocupa um lugar, uma função. Familia é um grupo de pessoas unidas pelos laços de afetividade $e$, às vezes, de consanguinidade. Então, seu cerne é o afeto. [grifos nossos]

No recorte (R2), observa-se que a noção de família não se constitui pelo modelo, mas pelas inúmeras representações sociais. Este modo de conceber família rompe com o imaginário da palavra família apresentado na Declaração Universal dos Direitos Humanos (1948), na Constituição Federal (1988) e na proposta do Estatuto da Família (2015). Ao considerar a família um elemento da cultura, o sujeito inscreve-se num discurso antropológico e nos remete ao trabalho de Lévi-Strauss (1982), no qual o autor refuta a ideia de que o átomo do parentesco seja a unidade biológica em favor da ideia de que o parentesco além, da descendência e da consanguinidade, se dá, sobretudo, pela aliança.

A formulação colocar essa imposição de que família é só a união de homem e mulher, isso ai é um retrocesso histórico, marca pelo/no dizer as formações imaginárias de família. Para o entrevistado, institucionalizar a família como modelo único é denegar toda a história da evolução familiar em nossa sociedade, ou seja, família se significa pelas relações de afeto e não pelo modelo.

A questão que se evoca é como os sentidos de família estabilizados nos textos jurídicos se entrecruzam com os outros sentidos em funcionamento na sociedade contemporânea, levando em consideração que o sujeito, ao dizer, inscreve-se em uma formação discursiva?

O recorte (R3), parte do fragmento do texto de Ronaldo Fonseca (ProsDF) ${ }^{20}$, que na posição de relator do Estatuto da Família, em 2015 pontua que:

${ }^{19} \mathrm{Cf} . \quad<$ http://www.blogdokennedy.com.br/estatuto-da-familia-e-enorme-retrocessohistorico/>. Acesso em: 21/09/17.

${ }^{20} \mathrm{Cf} . \quad<$ http://www.conjur.com.br/2015-fev-22/processo-familiar-estatuto-familia-foraprovado-stf-julgara-inconstitucional $>$. Acesso em: 26/09/2015. 
R3. faz-se necessário diferenciar família das relações de mero afeto, convívio e mútua assistência; sejam essas últimas relações entre pessoas de mesmo sexo ou de sexos diferentes, havendo ou não prática sexual entre essas pessoas. É importante asseverar que apenas da família, união de um homem com uma mulher, há a presunção do exercício desse relevante papel social que a faz ser base da sociedade. [grifos nossos].

Observa-se pelo R3 uma posição sujeito-legislador, que afetada ideologicamente como representação de uma parcela da população, compreende família como o modelo tradicional - a união entre um homem e uma mulher. Ao dizer diferenciar família das relações de mero afeto, convívio e mútua assistência [...] apenas da família, união de um homem com uma mulher, [...] relevante papel social que a faz ser base da sociedade, o sujeito se coloca no lugar daqueles que (re)afirmam a necessidade de manter "os indivíduos enquadrados nos padrões morais escolhidos como seguros". (LAGAZZI, 1987, p. 41). Aos sujeitos-de-direito determina-se, pelas Leis e pela defesa do sujeito-legislador, o que deve e o que não deve ser considerado família, produzindo um imaginário de língua capaz de completude.

Ao dizer diferenciar família das relações de mero afeto, convívio e mútua assistência [...]apenas da família, união de um homem com uma mulher, a formulação aponta para o lugar do político na linguagem. Há uma divisão de sentidos na palavra família, de um lado, o sentido imposto pelo discurso jurídico, de outro, o sentido que escapa ao que é imposto. Com efeito, o que se produz com essa divisão é a exclusão do sentido não institucionalizado de família.

Ao afirmar que pessoas que se agregam pelas relações de mero afeto, convívio e mútua assistência não constituem família, portanto, não constituem a base da sociedade, os sentidos produzidos, na formulação, não só silenciam outros modos de funcionamento de união familiar na contemporaneidade brasileira, como também desvinculam os efeitos de sentido de família, de casamento e de uma questão de gênero (homem e mulher).

Orlandi (2007, p. 96) afirma que "os aparelhos de poder de nossa sociedade geram a memória coletiva. Dividem os que estão autorizados a ler, a falar e escrever [...] dos outros, os que fazem os gestos repetidos que impõem aos sujeitos seu apagamento atrás da instituição". A formação discursiva, na qual se inscreve a posição sujeito-legislador, é afetada por uma memória discursiva de um princípio regulador determinado pelo jurídico.

Como vimos, as formações discursivas (R1) e (R2) se tocam por defender a pluralidade da união familiar, opondo-se à formação discursiva do (R3) que reconhece a família somente na união entre um homem e uma mulher.

Os sentidos das FDs (1) e (2) não migram para a FD (3), e se movem paralelamente, produzindo efeitos que intervêm nos discursos. Podemos dizer, desse modo, que as duas primeiras formações discursivas são dominantes e se opõem à terceira formação discursiva, cuja prática discursiva mesmo amparada legalmente vem sofrendo rupturas em relação ao avanço de um novo discurso que se impõe na sociedade brasileira.

Vejamos as formações discursivas: 
(R1) família é quem ama, cuida, instrui, humaniza, transmite valores, apresenta o que conhece de bom no mundo, protege, é presente, troca incontáveis fraldas, levanta de madrugada, conta histórias antes de dormir, leva pra escola, faxina a casa, cozinha, trabalha. (Renata Campello)

(R2) família é plural, tem inúmeras representações sociais. [...] Família é um elemento da cultura. [...]. Família é um grupo de pessoas unidas pelos laços de afetividade. (Rodrigo Cunha)

(R3) família é a união de um homem com uma mulher. (Ronaldo Fonseca / Pros-DF).

Podemos observar que os sentidos produzidos em (R3), cristalizados ao longo da história, produzem a ilusão de completude, de que este é o único modelo capaz de funcionar socialmente. Entretanto, os sentidos produzidos em (R1) e (R2) são da ordem da contradição, pois rompem com o já-dito discursivizado em (R3), e apontam para outros discursos, mostrando outros modos de funcionamento de união familiar na contemporaneidade brasileira. Família em (R1) e (R2) significa a união entre pessoas com base no afeto, opondo-se ao (R3), no qual família significa a união entre um homem e uma mulher.

É importante pensar que o sentido de uma palavra, expressão, proposição, etc., conforme Pêcheux (2009, p. 146), não existe "em si mesmo", o sentido "é determinado pelas posições ideológicas que estão em jogo no processo sócio-histórico no qual as palavras, expressões e proposições são produzidas". Esta posição nos permite depreender que pelo funcionamento da linguagem, as palavras tomam diferentes texturas, que têm a ver pelo modo como essas palavras vão sendo produzidas em distintas condições de produção e pelas posições ideológicas que estão em jogo no discurso.

\section{PALAVRAS FINAIS}

Podemos dizer que a palavra família aponta para sentidos diferentes, conforme a posição-sujeito de quem diz, para quem diz. Lenin apud Indursky ${ }^{21}$ diz "o um se divide em dois". Neste sentido, família é o uno que se divide em dois, porque os sentidos deslizam para formações discursivas distintas: família significando a união entre um homem e uma mulher e família significando a união entre pessoas com base no afeto.

Os diferentes sentidos que se estabelecem na palavra família apontam para uma dualidade: de um lado, a permanência do que está posto pelo Jurídico e, de outro, o movimento dos excluídos que lutam pela igualdade dos direitos civis. Cada ocorrência da palavra família se dá em condições de produção distintas que a fazem significar de modo particular. O conjunto destas ocorrências constitui a

\footnotetext{
${ }^{21}$ Cf. INDURSKY, Freda. Remontando de Pêcheux a Foucault: uma leitura em contraponto. $<$ http://www.ufrgs.br/analisedodiscurso/anaisdosead/1SEAD/Paineis/Freda Indursky.pdf $>$. Acesso em: 02/08/2017.
} 
memória discursiva da palavra família. No jogo da formulação, ao dizer família, esta palavra significa além do que o sujeito quer dizer, ou seja, significa uma memória discursiva de sentidos já constituídos, esquecidos ou desconhecidos, pois, o sujeito não tem controle de como os sentidos se formam.

Finalizando, a palavra família não significa o mesmo para distintas posições-sujeito que constituem a sociedade, uma vez que ao se inscrever em uma dada formação discursiva, como já foi elaborado por Pêcheux (2009, p. 146), "as palavras [...] mudam de sentido segundo as posições sustentadas por aqueles que as empregam", ou seja, "as palavras [...] não têm um sentido que lhe seria "próprio", vinculado a sua literalidade" (Ibidem, p. 147). Nesse sentido, a luta pela inclusão de modelos familiares não-ditos na proposta do Estatuto da Família e, consequentemente, nas Leis que regem o Brasil, é um assunto que não se esgota pelos efeitos de sentido que produz.

\section{REFERÊNCIAS}

BÍBLIA SAGRADA. Tradução, introdução e notas: Ivo Storniolo \& Euclides Martins Balancin. São Paulo: Paulus Editora, 1990.

BRASIL. Constituição da República Federativa do Brasil. Brasília, DF: Senado Federal: Subsecretaria de Edições Técnicas, 2001.

COUlangeS, Fustel de. $\boldsymbol{A}$ Cidade Antiga. Tradução de Frederico Ozanam Pessoa de Barros. Editora das Américas S.A. EDAMERIS, São Paulo, 1961. Versão digital eBooksBrasil, 2006.

COURTINE, Jean-Jacques. Le tessi de la mémoire: quelques perspectives de travail historique dans les sciences du langage. In: Langages, $28^{\circ}$ année, $\mathrm{n}^{\circ} 114$, 1994. Mémoire, histoire, langage. p. 5 - 12.

GADET, Francaise \& HAK, Tony (Orgs). Por uma análise automática do discurso: uma introdução a obra de Michel Pêcheux. 3.ed. Tradução de Bethania S. Mariani... [et al] - 3. ed. - Campinas: Editora da UNICAMP, 1997, (Coleção Repertories).

FOUCAULT, Michel. L'Ordre du discours: Leçon inaugurale ao Collège de France prononcée le 2 décembre 1970. Tradução de Edmundo Cordeiro \& António Bento. Éditions Gallimard, Paris, 1971.

LAGAZZI-RODRIGUES, Suzy. O juridismo marcando as palavras: uma análise de discurso cotidiano. Dissertação de Mestrado. IEL/UNICAMP. Campinas, São Paulo. 1987.

LÉVI-STRAUS, Claude. As estruturas elementares do parentesco (1949). Tradução de Mariano Ferreira. Petrópolis: Vozes, 1982. 
MOTTA, Ana Luiza Artiaga Rodrigues da. "Interpretação: O discurso constitucional e o processo de individualização do sujeito". In: Linguagem e Interpretação: A institucionalização dos dizeres na história. BRESSANIN, Joelma Aparecida [et al]. (Orgs.), Campinas: Editora RG, 2013.

ORLANDI, E. P. Análise de discurso: Princípios \& procedimentos. 7. ed. Campinas: Pontes, 2007.

. As formas do silêncio: no movimento dos sentidos. 6. ed. Campinas: editora Unicamp, 2007.

. Interpretação: autoria, leitura e efeitos do trabalho simbólico. 5. ed.

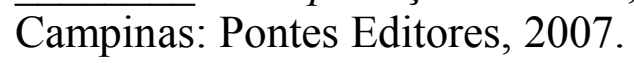

. Discurso e texto: Formulação e circulação dos sentidos. 3. ed. Campinas: Pontes Editores, 2008.

. "Silêncio e Implícito (Produzindo a monofonia)." In: História e Sentido na Linguagem. GUIMARÃES, Eduardo (Org.) $2^{\mathrm{a}}$ edição aumentada, Campinas: Editora RG, 2008.

\& LAGAZZI-RODRIGUES, Suzy. (Orgs.).” Análise de Discurso.” In:

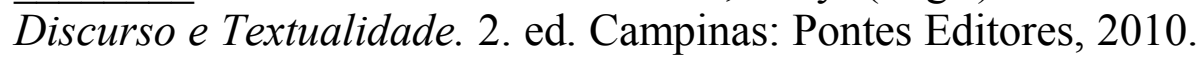

. "Documentário: acontecimento discursivo, memória e interpretação." In: ZANDWAIS, Ana. (Orgs.). Leituras do politico. Porto Alegre: Editora da UFRGS, 2011.

PAYER, Maria Onice. Memória da língua: imigração e nacionalidade. São Paulo: Escuta, 2006.

PRADO, Danda. O que é família. São Paulo: Abril Cultural: Brasiliense, 1985.

PÊCHEUX, Michel. O discurso: estrutura e acontecimento. Tradução Eni P. Orlandi. $5^{\text {a }}$ ed. Campinas: Pontes Editores, 2008.

. Semântica e discurso: uma crítica à afirmação do óbvio. Tradução de Eni Puccinelli Orlandi [et al.]. 4. ed. Campinas: Editora da Unicamp, 2009.

PEREIRA, Virgílio de Sá. Lições de Direito de família. 2. ed. Rio de Janeiro: Freitas Bastos, 1959.

ROUSSEAU, Jean-Jacques. Do contrato social. Tradução: Rolando Roque da Silva. São Paulo: Abril Cultural, 1983. Série Os Pensadores. 
ZATTAR, Neuza. "A fala do trono: o discurso imperial sem coroa" In: Linguagem, História e Memória: Discursos em movimento. Ana Maria Di Renzo et al. (Orgs.). Campinas: Pontes Editores, 2011.

Mara Lucia Martins Rodrigues

MaraLucia_Prof@hotmail.com

Ana Luiza Artiaga Rodrigues da Motta AnaLuizArt@unemat.br

Recebido em: 1 mar. 2018

Aceito em: 11 abr. 2018

Publicado em: 19 ago. 2018 